\title{
NOTE
}

\section{Rapid ontogenetic shift in juvenile Pacific bluefin tuna diet}

\author{
Takashi Kitagawa $^{1, *}$, Ko Fujioka ${ }^{2}$ \\ ${ }^{1}$ Atmosphere and Ocean Research Institute, The University of Tokyo, 5-1-5 Kashiwanoha, Kashiwa, Chiba 277-8564, Japan \\ ${ }^{2}$ National Research Institute of Far Seas Fisheries, Japan Fisheries Research and Education Agency, \\ Shimizu Laboratory: 5-7-1 Orido, Shimizu, Shizuoka 424-8633, Japan
}

\begin{abstract}
We measured white muscle isotopic compositions and aspect ratios (ARs) of caudal fins in juvenile Pacific bluefin tuna Thunnus orientalis (PBT) to examine ontogenetic dietary shifts and swimming ability. ARs averaged 3.9 in fish with fork length (FL) $<15 \mathrm{~cm}, 4.6$ in fish with FL of 30-35 cm, and 6.7 in adult fish with FL > $200 \mathrm{~cm}$. Mean isotope values of carbon and nitrogen in white muscle increased from -18.3 to $-18.0 \%$ and from +7.2 to $8.9 \%$ in $\sim 20 \mathrm{~cm}$ fish to $-16.5 \%$ and $+12.3 \%$ in 30-35 cm fish, respectively, with a shift at $25 \mathrm{~cm}$ FL. This shift was much earlier than that reported for yellowfin tuna $T$. albacares (40-50 cm FL). Our results suggest that, after moving to Japanese coastal areas and reaching a FL of $25 \mathrm{~cm}$, PBT rapidly develop swimming abilities by achieving endothermy and switching from a diet of small squid and zooplankton to a diet based on fish prey items that have greater body mass with higher calorific content and swimming ability. This may give them a selective advantage and allow high energetic expenditure.
\end{abstract}

KEY WORDS: Thunnus orientalis $\cdot$ Ontogeny $\cdot$ Endothermy $\cdot$ Prey diet $\cdot$ Aspect ratio $\cdot$ Juvenile $\cdot$ Stable isotope analysis

\section{INTRODUCTION}

Pacific bluefin tuna Thunnus orientalis (PBT) are widely distributed in the North Pacific Ocean and are among the most important fisheries species in Japan. PBT spawn from April to June in spawning grounds located between the Philippines and the Ryukyu Islands of Japan, and in August in the Sea of Japan (e.g. Okiyama 1974, Chen et al. 2006, Tanaka et al. 2007). After being transported by sea currents to Japanese coastal areas (e.g. by the Kuroshio Current) at 60-90 d after hatching (Kitagawa et al. 2010), juvenile $(<1 \mathrm{yr}$, fork length [FL] of 15-60 cm) PBT remain in coastal waters around Japan (e.g. Bayliff 1994, Kitagawa et al. 2000).

The Japanese catch of juvenile PBT accounts for $59 \%$ of the total catch in the Pacific Ocean (Itoh

*Corresponding author: takashik@aori.u-tokyo.ac.jp
2001), and ecological information on this juvenile stage may prove useful in developing an ecosystem approach to fisheries management. Therefore, to understand the growth and migration patterns of juvenile PBT, knowledge of their feeding habits would be useful. Shimose et al. (2013) focused on the dietary composition of juvenile PBT and suggested that PBT switch to a diet based more on fish prey items after they reach a size of $25 \mathrm{~cm} \mathrm{FL}$; the switch to prey species with a greater body mass and swimming ability than small squid and zooplankton indicates the acquisition of diving and swimming abilities associated with endothermy in the fish. In the present study, we measured white muscle isotopic compositions and aspect ratios (ARs) of caudal fins to examine ontogenetic dietary shifts and swimming abilities in juvenile PBT.

() The authors 2017. Open Access under Creative Commons by Attribution Licence. Use, distribution and reproduction are unrestricted. Authors and original publication must be credited. 


\section{MATERIALS AND METHODS}

ARs were calculated to provide an index of the swimming ability of PBT. ARs estimate the degree to which the fin is 'wing-like;' fish with a higher AR should be more efficient and faster swimmers, all else being equal (e.g. Magnuson 1978). In total, 225 fish, including those used for stable isotope analyses, were collected around Japan (Tsushima Island, Kochi, Wakayama, Kanagawa, Ishigaki Island, Sado Island, Tottori, Iwate, and Yamagata) from 2009 to $2014(12,23,5,122,37$, and 26 fish were collected in 2009, 2010, 2011, 2012, 2013, and 2014, respectively). FLs ranged from 13.5 to $263 \mathrm{~cm}$. Caudal fins were photographed using a digital camera, and the AR was calculated using Image J (https:// imagej.nih.gov/ij/) as: (fin span) ${ }^{2} /$ fin area. The relationship between body size and AR was analyzed using linear regression (Magnuson 1978).

Samples of white muscle were obtained from 140 fish with FLs ranging from 13.5 to $61.0 \mathrm{~cm}$; these samples were collected from fish caught around Japan (Tsushima Island, Kochi, and Kanagawa) from 2008 to $2012(2,12,15,5$, and 106 samples in 2008, 2009, 2010, 2011, and 2012, respectively). The samples were analyzed for carbon and nitrogen stable isotopic compositions. Samples were oven-dried at $60^{\circ} \mathrm{C}$ for $24 \mathrm{~h}$, then ground to a fine powder using a spatula. Lipids within the sample were then removed by adding a 1:1 mixture of chloroform and methanol and centrifuging at $2795 \times g(5 \mathrm{~min})$; the supernatant was removed and dried (these steps were repeated twice). An aliquot (0.5-1.0 mg) of each sample was then sealed in a tin capsule. Stable isotope ratios were analyzed using an elemental analyzer (Carlo Erba EA1108 and Thermo Electron FLASH EA1112) interfaced with a mass spectrometer (Finnigan Mat Delta S and Finnigan Mat DeltaPlusXP) via a Conflo II and Conflo III open split interface. Isotopic ratios of carbon and nitrogen are reported as delta $(\delta)$ values (\%) with respect to Vienna Pee Dee Belemnite (VPDB) and atmospheric $\mathrm{N}_{2}$, respectively, based on the analysis of alanine working standards (Shoko Science); isotopic values were confirmed by traceable international reference materials (e.g. IAEA, NBS). The error of measurement was within $\pm 0.25 \%$ for $\delta^{13} \mathrm{C}$ and $\delta^{15} \mathrm{~N}$ analyses.

\section{RESULTS}

Fig. 1 shows the relationship between body size (FL) and ARs in PBT. To our knowledge, these are the first comprehensive data for ARs of PBT measured over a wide range of body sizes. The mean $( \pm \mathrm{SD}) \mathrm{AR}$ of fish with FL $<15 \mathrm{~cm}$ was $3.9 \pm 0.59$; this increased rapidly with fish growth, although there was some variability among individuals. Mean AR was $4.6 \pm$ 0.84 for 30-35 cm fish (Table 1). Subsequently, mean AR increased to $6.7 \pm 0.73$ for fish $>200 \mathrm{~cm}_{i}$ in adult fish $>114 \mathrm{~cm}$ (Okochi et al. 2016), ARs ranged from 4.5 (115 cm fish) to 8.2 (208 cm fish; Fig. 1). Piecewise linear regression showed a break point around 30.3-30.4 cm FL (sum of residual sum of squares =

Table 1. Mean $\pm \mathrm{SD}$ of $\delta^{13} \mathrm{C}$ and $\delta^{15} \mathrm{~N}$ values of white muscle, and caudal fin aspect ratio (AR) of Pacific bluefin tuna over a range of body sizes (fork length, FL). Numbers in parentheses are sample sizes; na: not assessed

\begin{tabular}{|lccc|}
\hline FL $(\mathrm{cm})$ & $\delta^{15} \mathrm{~N}(\%)$ & $\delta^{13} \mathrm{C}(\%)$ & $\mathrm{AR}$ \\
\hline$<15$ & $+7.2 \pm 0.43(5)$ & $-18.0 \pm 0.19$ & $3.9 \pm 0.59(4)$ \\
$15-20$ & $+8.9 \pm 0.84(27)$ & $-18.3 \pm 0.37$ & $3.3 \pm 0.65(25)$ \\
$20-25$ & $+9.7 \pm 0.60(42)$ & $-17.9 \pm 0.35$ & $4.1 \pm 0.85(40)$ \\
$25-30$ & $+11.1 \pm 1.25(25)$ & $-17.3 \pm 0.74$ & $4.4 \pm 0.70(27)$ \\
$30-35$ & $+12.3 \pm 1.74(17)$ & $-16.5 \pm 0.93$ & $4.6 \pm 0.84(20)$ \\
$35-60$ & $+12.4 \pm 0.28(23)$ & $-17.3 \pm 0.65$ & $4.9 \pm 0.70(22)$ \\
$60-100$ & $+11.9(1)$ & -17.0 & $6.0 \pm 0.87(5)$ \\
$100-200$ & na & na & $6.1 \pm 0.77(61)$ \\
$>200$ & na & na & $6.7 \pm 0.73(21)$ \\
\hline \multicolumn{5}{c}{} \\
\hline
\end{tabular}



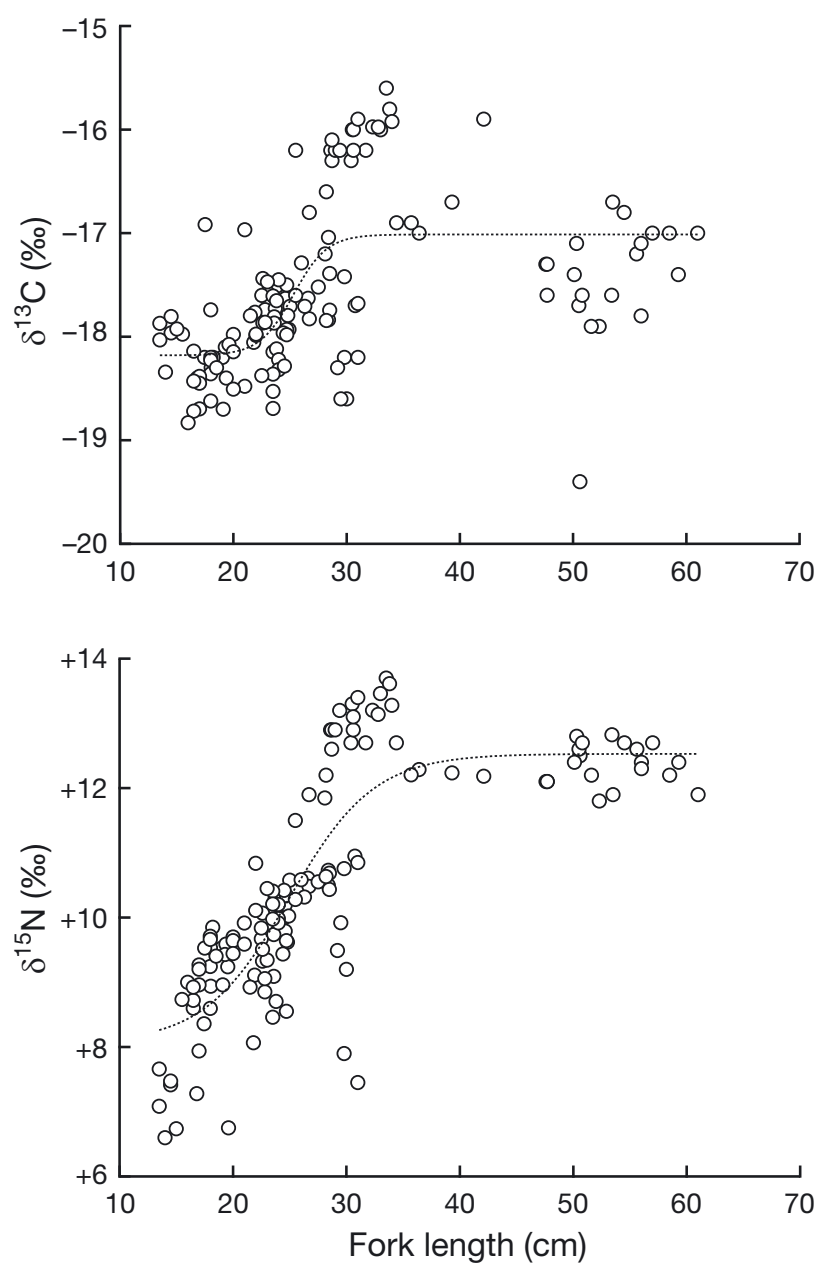

Fig. 2. $\delta^{13} \mathrm{C}$ and $\delta^{15} \mathrm{~N}$ values of Pacific bluefin tuna (PBT) white muscle over a range of fork lengths (FL). A 4-parameter sigmoid model was fitted to the PBT white muscle tissue $\left(\delta^{13} \mathrm{C}=\right.$ $-18.2+1.2 /\{1+\exp [-(\mathrm{FL}-25.3) / 1.50]\}, \mathrm{R}^{2}=0.43 ; \delta^{15} \mathrm{~N}=$ $\left.8.1+4.5 /\{1+\exp [-(F L-25.0) / 0.85])\}, R^{2}=0.69\right)$

116.3). The slope of the smaller-sized group was approximately 10 times greater than that of the largersized group (Fig. 1).

Mean $\delta^{13} \mathrm{C}$ values were -18.3 and $-18.0 \%$ for fish $<15$ and $20 \mathrm{~cm}$, respectively, but increased with fish growth, and were $-16.5 \%$ for $30-35 \mathrm{~cm}$ fish; $\delta^{13} \mathrm{C}$ values were stable in larger fish, i.e. $>35 \mathrm{~cm}$ (Table 1 , Fig. 2). Regression analysis showed a distinct positive shift in $\delta^{13} \mathrm{C}$ in the white muscle tissue of $25-30 \mathrm{~cm}$ individuals (Fig. 2). White muscle carbon isotope values were related to FL: fish $<25.0 \mathrm{~cm}(-18.0 \% \pm 0.39$, $\mathrm{n}=74$ ) showed significant differences from fish $>25.0 \mathrm{~cm}(-17.1 \%$ o 0.82, $\mathrm{n}=66$; $\mathrm{p}<0.0001$, Student's $t$-test).

Mean $\delta^{15} \mathrm{~N}$ values were +7.2 and $8.9 \%$ for fish $<15$ and $20 \mathrm{~cm}$, respectively; isotope levels increased with fish size and were $+12.3 \%$ for $30-35 \mathrm{~cm}$ fish; the levels were stable in fish of larger sizes, i.e. $>35 \mathrm{~cm}$ (Table 1). Regression analysis showed a distinct positive shift in $\delta^{15} \mathrm{~N}$ in the white muscle tissue of $25-30 \mathrm{~cm}$ individuals (Fig. 2). The $\delta^{15} \mathrm{~N}$ values of fish $<25.0 \mathrm{~cm}(+9.2 \% \pm 0.94, \mathrm{n}=74)$ were significantly lower than those of fish $>25.0 \mathrm{~cm}(+11.9 \% \pm \pm 1.31, \mathrm{n}=$ $66 ; \mathrm{p}<0.0001$, Student's $t$-test). Fish of $25-35 \mathrm{~cm}$ exhibited a large range of $\delta^{15} \mathrm{~N}$ values relative to the smaller-sized fish, but fish $>32 \mathrm{~cm}$ had a narrow range (Fig. 2).

\section{DISCUSSION}

When PBT arrived in Japanese coastal waters after being transported by sea currents from the spawning grounds at 60-90 d after hatching, the ARs of caudal fins were 3.9 on average for fish of $13.5-15 \mathrm{~cm} \mathrm{FL}$; AR increased rapidly with fish growth and reached 4.6 on average for $30-35 \mathrm{~cm}$ fish (Table 1). This value is within the previously reported scombrid range of about 4 to 9 (Westneat \& Wainwright 2001). Although the soft rays of the caudal fin develop in juvenile PBT, differences in their further development may explain why AR values vary among individuals. Subsequently, ARs increased to 6.7 on average for fish $>200 \mathrm{~cm}$, which were approximately 9 yr old (Shimose et al. 2009). Tanaka et al. (2006) reported that $16.7-30.0 \mathrm{~cm}$ PBT appeared in waters off Kochi Prefecture at 54 to $89 \mathrm{~d}$ of age. Therefore, taking the slope value into consideration, it is suggested that they grow rapidly and gain greater swimming ability in the 1 to $2 \mathrm{mo}$ after arriving in Japanese coastal waters.

During this time, mean $\delta^{13} \mathrm{C}$ and $\delta^{15} \mathrm{~N}$ values increased from -18.3 to $-18.0 \%$ and from +7.2 to $8.9 \%$ o for $<15-20 \mathrm{~cm}$ fish, to $-16.5 \%$ and $+12.3 \%$ for $30-$ $35 \mathrm{~cm}$ fish, respectively (Table 1). Ecological theory suggests that a trophic level is represented by a shift of $\sim 0.8 \%$ and $\sim 3.4 \%$ in $\delta^{13} \mathrm{C}$ and $\delta^{15} \mathrm{~N}$ values, respectively, between prey and predator (DeNiro \& Epstein 1978, Minagawa \& Wada 1984). Thus, differences greater than these values between the smallest and larger PBT size classes imply that there are 2 steps between their trophic levels of the prey consumed, although $\delta^{13} \mathrm{C}$ and $\delta^{15} \mathrm{~N}$ values of prey could not be analyzed in this study. Our results also showed that $\mathrm{C}$ and $\mathrm{N}$ isotope values in white muscle tissue changed in fish $>25 \mathrm{~cm}$; this result is consistent with previous studies of stomach contents (Shimose et al. 2013, Shimose \& Wells 2015). This alteration in isotope values was considered an ontogenetic change rather than a seasonal change as this pelagic species is unlikely to change over a short seasonal scale (ca. 2 mo) (Shi- 
mose et al. 2013). Shimose et al. (2013) reported that the pattern of dietary shifts were similar in 2 regions: in the Tsushima Current region (Sea of Japan), small PBT (20-25 cm FL) prey upon small squid (juvenile Enoploteuthis chunii), and larger PBT $(25-35 \mathrm{~cm})$ gradually shift their diet to the mesopelagic fish Maurolicus japonicus (as suggested by Kitagawa et al. 2000, 2004); in the Kuroshio region (Pacific Ocean), small PBT $(20-25 \mathrm{~cm})$ prey on small zooplankton (mostly crustacean larvae), and larger PBT $(25-40 \mathrm{~cm})$ shift to epipelagic fishes (Etrumeus teres, Sardinops melanostictus, and Engraulis japonicus). This suggests that, after PBT reach $25 \mathrm{~cm}$, the $\delta^{15} \mathrm{~N}$ shift to a higher tropic level found here reflects a switch to a diet based more on fish prey items which have greater body mass and higher calorific content than small squid and zooplankton. For example, calorific values of E. teres, S. melanostictus, and $E$. japonicus are 136, 169, and $192 \mathrm{kcal}$ per $100 \mathrm{~g}$, respectively, whilst that of a small squid of the Enoploteuthidae is $84 \mathrm{kcal}$ per $100 \mathrm{~g}$ (http://fooddb. mext.go.jp/).

Ontogenetic dietary shift in PBT occurs at a smaller size than that reported for yellowfin tuna Thunnus albacares; this shift occurs at 40-50 cm FL in Sri Lankan waters (Maldeniya 1996) and at 45$50 \mathrm{~cm}$ FL around Hawaii, USA (Graham et al. 2007). This difference in dietary shift between PBT and yellowfin tuna possibly reflects the difference in sizes between pelagic fauna in temperate and tropical areas (Shimose et al. 2013). Additionally, this effect might also be attributed to the acquisition of endothermy at smaller sizes, which enables PBT to adapt to temperate waters compared to yellowfin tuna that are distributed in warmer waters. Ontogenetic shifts in other related species, such as Atlantic bluefin tuna T. thynnus, also occur at a smaller size; for example, at $21-35 \mathrm{~cm} \mathrm{FL}$, the proportion of crustaceans in stomach contents decreases (Sinopoli et al. 2004). However, the patterns of dietary shift are different from those in PBT (Shimose et al. 2013). In particular, ambient temperatures around the Japanese coastal areas $\left(24.5-29.0^{\circ} \mathrm{C}\right.$ ) are favorable for PBT growth only during August and September (Kitagawa et al. 2010); therefore, PBT might have to acquire endothermy before the favorable temperatures decrease. This conclusion is consistent with the findings of Funakoshi et al. (1985) and Kubo et al. (2008), who reported that the body (red muscle) temperature of PBT $>30 \mathrm{~cm}$ FL was higher than ambient temperature, probably because of the development of an endothermy system, such as rete mirabile.
As demonstrated by juvenile black skipjack tuna Euthynnus lineatus, there appears to be a minimum size for functional endothermy of $\sim 10 \mathrm{~cm}$ FL or $163 \mathrm{~g}$ body mass (Dickson 1994, Dickson et al. 2000). Therefore, it should be noted that, although nascent endothermic capabilities might be present in very small size classes of PBT, their high surface area: volume ratio might overwhelm the ability of the countercurrent heat exchangers to buffer the effects of changes in ambient temperature associated with vertical diving (Dickson et al. 2000, Graham et al. 2007). This should be examined further to confirm the minimum size for functional endothermy in PBT.

Endothermy may have evolved to enable high performance in PBT by delivering oxygen and metabolic substrates to tissues at high rates and to allow rapid somatic and gonadal growth, rapid digestion, and rapid recovery from exhaustive exercise, rather than for exceptionally high, sustained swimming speed (Brill 1996). However, endothermy involves high energetic (metabolic) costs to produce body heat: more than $80 \%$ of the assimilated energy flow is dissipated at a size of $>35 \mathrm{~cm}$ (Jusup \& Matsuda 2015). Therefore, PBT may need to switch to a diet based more on fish prey items that have a greater calorie content. In summary, after moving to Japanese coastal areas in summer, PBT rapidly develop their swimming abilities and acquire endothermy to aid efficiency of foraging in colder waters after they reach $25 \mathrm{~cm}$ FL; these developmental changes are accompanied by a switch to a diet based more on fish prey items that have greater body mass and swimming ability. The shift from ectothermy to endothermy may give them a selective advantage and allow high energetic expenditure.

Acknowledgements. We thank T. Goto (Iwate University), S. Harada (Wakayama Prefectural Fisheries Experiment Station), M. Kudo (Yamagata Prefecture), I. Ohta (Okinawa Prefectural Fisheries Research and Extension Center), and T. Shimose (Seikai National Fisheries Research Institute) for sample collection, and K. Shirai (Atmosphere and Ocean Research Institute, the University of Tokyo) and the anonymous referees for constructive criticism of the manuscript. This work was supported by JSPS KAKENHI Grant Numbers JP20688009, JP24380104, JP16H01769, and Cooperative Research Organization for the Promotion Program of International Fisheries Stock Assessment from the Fisheries Agency of Japan. We thank Editage for English language review.

\section{LITERATURE CITED}

Bayliff WH (1994) A review of the biology and fisheries for northern bluefin tuna, Thunnus thynnus, in the Pacific Ocean. FAO Fish Tech Pap 336:244-295 
Brill RW (1996) Selective advantages conferred by the high performance physiology of tunas, billfishes, and dolphin fish. Comp Biochem Physiol A Physiol 113:3-15

Chen KS, Crone P, Hsu CC (2006) Reproductive biology of female Pacific bluefin tuna Thunnus orientalis from south-western North Pacific Ocean. Fish Sci 72:985-994

DeNiro MJ, Epstein S (1978) Influence of diet on distribution of carbon isotopes in animals. Geochim Cosmochim Acta 42:495-506

Dickson K (1994) Tunas as small as $207 \mathrm{~mm}$ fork length can elevate muscle temperatures significantly above ambient water temperature. J Exp Biol 190:79-93

*Dickson KA, Johnson NM, Donley JM, Hoskinson JA, Hansen MW, Tessier J (2000) Ontogenetic changes in characteristics required for endothermy in juvenile black skipjack tuna (Euthynnus lineatus). J Exp Biol 203: 3077-3087

Funakoshi S, Wada K, Suzuki T (1985) Development of the rete mirabile with growth and muscle temperature in the young bluefin tuna. Bull Jpn Soc Sci Fish 51:1971-1975

Graham BS, Grubbs D, Holland K, Popp BN (2007) A rapid ontogenetic shift in the diet of juvenile yellowfin tuna from Hawaii. Mar Biol 150:647-658

Itoh T (2001) Estimation of total catch in weight and catchat-age in number of bluefin tuna Thunnus orientalis in the whole Pacific Ocean. Bull Nat Res Inst Far Seas Fish 38:83-111

Jusup M, Matsuda H (2015) Mathematical modeling of bluefin tuna growth, maturation, and reproduction based on physiological energetics. In: Kitagawa $T$, Kimura $S$ (eds) Biology and ecology of bluefin tuna. CRC Press, Boca Raton, FL, p 369-399

Kitagawa $T$, Nakata $H$, Kimura S, Itoh T, Tsuji S, Nitta A (2000) Effect of ambient temperature on the vertical distribution and movement of Pacific bluefin tuna Thunnus thynnus orientalis. Mar Ecol Prog Ser 206:251-260

Kitagawa T, Kimura S, Nakata H, Yamada H (2004) Diving behavior of immature, feeding Pacific bluefin tuna (Thunnus thynnus orientalis) in relation to season and area: the East China Sea and the Kuroshio-Oyashio transition region. Fish Oceanogr 13:161-180

Kitagawa T, Kato Y, Miller MJ, Sasai Y, Sasaki H, Kimura S (2010) The restricted spawning area and season of Pacific bluefin tuna facilitate use of nursery areas: modeling approach to larval and juvenile dispersal processes. J Exp Mar Biol Ecol 393:23-31

Kubo T, Sakamoto W, Murata O, Kumai H (2008) Whole-

Editorial responsibility: Stylianos Somarakis,

Heraklion, Greece body heat transfer coefficient and body temperature change of juvenile Pacific bluefin tuna Thunnus orientalis according to growth. Fish Sci 74:995-1004

Magnuson JJ (1978) Locomotion by scombrid fishes: hydromechanics, morphology, and behavior. In: Hoar WS, Randall DJ (eds) Fish physiology, Vol 7. Academic Press, New York, NY, p 239-313

Maldeniya R (1996) Food consumption of yellowfin tuna, Thunnus albacares, in Sri Lankan waters. Environ Biol Fishes 47:101-107

Minagawa M, Wada E (1984) Stepwise enrichment of ${ }^{15} \mathrm{~N}$ along food chains: further evidence and the relation between $\delta^{15} \mathrm{~N}$ and animal age. Geochim Cosmochim Acta 48:1135-1140

Okiyama M (1974) Occurrence of the postlarvae of bluefin tuna, Thunnus thynnus, in the Japan Sea. Bull Jpn Sea Fish Res Lab 25:89-97

Okochi Y, Abe O, Tanaka S, Ishihara Y, Shimizu A (2016) Reproductive biology of female Pacific bluefin tuna, Thunnus orientalis, in the Sea of Japan. Fish Res 174:30-39

Shimose T, Wells RD (2015) Feeding ecology of bluefin tunas. In: Kitagawa T, Kimura S (eds) Biology and ecology of bluefin tuna. CRC Press, Boca Raton, FL, p 47-77

Shimose T, Tanabe T, Chen KS, Hsu CC (2009) Age determination and growth of Pacific bluefin tuna, Thunnus orientalis, off Japan and Taiwan. Fish Res 100:134-139

Shimose T, Watanabe H, Tanabe T, Kubodera T (2013) Ontogenetic diet shift of age-0 year Pacific bluefin tuna Thunnus orientalis. J Fish Biol 82:263-276

* Sinopoli M, Pipitone C, Campagnuolo S, Campo D, Castriota L, Mostarda E, Andaloro F (2004) Diet of young-of-theyear bluefin tuna, Thunnus thynnus (Linnaeus, 1758), in the southern Tyrrhenian (Mediterranean) Sea. J Appl Ichthyol 20:310-313

* Tanaka Y, Satoh K, Iwahashi M, Yamada H (2006) Growthdependent recruitment of Pacific bluefin tuna Thunnus orientalis in the northwestern Pacific Ocean. Mar Ecol Prog Ser 319:225-235

* Tanaka Y, Mohri M, Yamada H (2007) Distribution, growth and hatch date of juvenile Pacific bluefin tuna Thunnus orientalis in the coastal area of the Sea of Japan. Fish Sci 73:534-542

Westneat MW, Wainwright SA (2001) Mechanical design for swimming: muscle, tendon, and bone. In: Block BA, Stevens ED (eds) Fish physiology, Vol 19. Tuna: physiology, ecology, and evolution. Academic Press, San Diego, CA, p 271-311

Submitted: December 14, 2016; Accepted: March 22, 2017 Proofs received from author(s): May 2, 2017 